\title{
Diseño y desarrollo de productos lácteos enriquecidos con grasas poliinsaturadas
}

\section{Design and development of dairy products enriched with polyunsaturated fats}

\author{
Jorge Vargas', Tarsila Tuesta², Gilberto García², Jonnatan Bañon², \\ Andres Chávez 3
}
${ }^{1}$ Laboratorio de Leche y Carnes, Facultad Zootecnía, Universidad Nacional Agraria, La Molina, Lima - Perú
${ }^{2}$ Facultad de Ingeniería Química y Textil, Universidad Nacional de Ingeniería, Lima - Perú
3Universidad Nacional Mayor de San Marcos, Lima - Perú

Recibido : 27/06/2017 Aceptado: 29/09/2017

\section{RESUMEN}

El objetivo de la presente investigación es diseñar y desarrollar queso fresco y yogurt enriquecidos con ácidos grasos poliinsaturados. Se utiliza como materia prima leche fresca y como aditivo fuente de ácidos grasos poliinsaturados al aceite de soya. El contenido de ácidos grasos poliinsaturados, que contiene el queso fresco elaborado con leche descremada y enriquecida con 2 a $4 \%$ de aceite de soya se elevó de 5,01\% a 54,83\%; el contenido de ácidos grasos poliinsaturados del yogurt natural elaborado con leche descremada y enriquecida con 1 a $3 \%$ de aceite de soya se elevó de 4,28\% a 54,98\%. Se concluye que es factible la producción de productos lácteos enriquecidos con ácidos grasos poliinsaturados y se recomienda su fabricación.

Palabras claves: Productos lácteos, Queso Fresco, Yogurt Natural, Aceite de Soya, Ácidos Grasos Poliinsaturados.

\begin{abstract}
The goal of this work has been to design and develop products such as fresh cheese and yogurt, enriched with polyunsaturated fatty acids. Fresh milk was used as raw material and soybean oil as source of polyunsaturated fatty acids. The content of polyunsaturated fatty acids in fresh cheese made from skim milk enriched with 2 to $4 \%$ soybean oil, increased from $5.01 \%$ to $54.83 \%$. Similarly, the content of polyunsaturated fatty acids in natural yogurt made from skim milk enriched with 1 to $3 \%$ soybean oil, increased from $4.28 \%$ to $54.98 \%$. We conclude that is feasible to produce dairy products enriched with polyunsaturated fatty acids and their manufacture is recommended.
\end{abstract}

Key words: dairy products, fresh cheese, natural yogurt, soybean oil, polyunsaturated fatty acids.

\section{INTRODUCCIÓN}

Las dietas con alto contenido de ácidos grasos saturados y bajo en ácidos grasos poliinsaturados, favorecen el origen de problemas cardiovasculares [1]. Estos problemas pueden ser prevenidos a través de dietas ricas en ácidos grasos poliinsaturados.

El consumo de ácidos grasos monoinsaturados y poliinsaturados es recomendado para una correcta alimentación frente a los ácidos grasos saturados [2], por lo que se aconseja el consumo de aceites vegetales.
En el Perú, la cantidad de alimentos consumidos como fuentes ricas en ácidos grasos poliinsaturados (huevos de codorniz, leches enriquecidas, yogur, etc.), es muy baja, lo cual responde a cuestiones de hábito alimentario, formas de preparación, poco conocimiento, así como la escaza comercialización de estos productos, que no están al alcance económico de las clases más necesitadas, por ejemplo: leche desnatada enriquecida con omega-3.

La mejor forma de aumentar el aporte de ácidos grasos poliinsaturados en la dieta del ser humano, para

\footnotetext{
* Correspondencia:

E-mail: jvargasm@lamolina.edu.pe, tarsilat@uni.edu.pe
} 
el caso del peruano medio, es consumiendo pescados y mariscos. También pueden consumirse alimentos enriquecidos con aceites de pescado, pero su consumo está limitado ya que ofrecen olores poco agradables.

Otra alternativa de alimentación con fuente de ácidos grasos poliinsaturados puede ser a través de aceites y semillas ricas en ácidos alfa linolénico y linoleico denominados ácidos grasos esenciales, tales como el aceite de soya, canola y de linaza; en el caso de estos dos últimos su importación es limitado por sus altos precios [3].

El objetivo de la presente investigación es elaborar yogur natural bebible y queso fresco enriquecido con aceite de soya, que tenga aceptabilidad sensorial.

\section{ASPECTOS GENERALES}

La leche es un líquido secretado por las glándulas mamarias de las hembras de los mamíferos tras el nacimiento de la cría, de composición compleja, blanca y opaca, de sabor dulce y reacción iónico, pH próximo a la neutralidad, como emulsión en fase dispersa está constituida por la materia grasa de forma globular, y como fase continua un líquido que muestra analogías con el plasma sanguíneo. Este líquido es asimismo una emulsión de materias proteicas en un suero constituido por una solución neutra que contiene principalmente, lactosa y sales minerales.

La leche tiene cuatro tipos de componentes importantes:

- Los lípidos, componentes esenciales de las grasas ordinarias; triglicéridos.

- Las proteínas; caseínas, albúminas y globulinas.

- Los glúcidos, esencialmente la lactosa.

- Las sales.

A ellos se añaden otros numerosos componentes, presentes en cantidades mínimas: lecitinas, vitaminas, enzimas, nucleótidos, gases disueltos, etc., algunos de los cuales tienen una gran importancia debido a su actividad biológica.

\subsection{Queso}

Conserva obtenida por coagulación de la leche, generalmente bajo la acción del cuajo. El coágulo se separa del suero y forma el queso, luego del desuerado y su maduración; contiene esencialmente la caseína y la grasa de la leche.

El queso es el producto sin madurar, obtenido por separación del suero después de la coagulación de la leche cruda o reconstituida, pasteurizada, entera o parcialmente descremada, o una mezcla de alguno de estos productos que cumpla con los requisitos especificados en la NTP 202.195:2004. El contenido acuoso oscila entre el 50 a $80 \%$ [4].

\subsection{Yogurt}

El yogurt es un alimento obtenido mediante fermentación de la leche por cultivos lácticos, permitiendo que la lactosa se transforme en ácido láctico y tenga una textura más espesa y un sabor más ácido y concentrado. El yogurt aporta naturalmente nutrientes como proteínas de alta calidad y calcio, el cual contribuye al mantenimiento de los huesos.

\subsection{Aceite de soya}

El aceite de soya, rico en ácidos grasos esenciales, figura entre los aceites más recomendados para la nutrición humana [5]. Contiene $15 \%$ de grasas saturadas, $23 \%$ de grasas monoinsaturadas, $55 \%$ de ácido linoleico $\omega-6$ y $7 \%$ de ácido linolénico $\omega-3$.

\section{4 Ácidos grasos insaturados}

Ácidos carboxílicos de cadena larga y lineal que contiene al menos un doble enlace a lo largo de la cadena. Ejemplo el ácido oleico.

\subsection{Clasificación de ácidos grasos insaturados}

Monoinsaturados.- Ácidos grasos que sólo presentan un doble enlace en su estructura. El ácido oleico, constituye las 3/4 partes de los ácidos grasos de esta categoría.

Poliinsaturados.- Ácidos grasos que tienen varios dobles enlaces en su estructura. Esta clasificación contiene a los ácidos grasos esenciales.

\section{Ácidos grasos esenciales}

Son aquellos ácidos que en su forma aislada, el organismo no los pueden sintetizar y es necesario ingerirlos con la dieta; también se les conoce como vitamina $\mathrm{F}$.

Existen dos variedades de ácidos grasos esenciales: Linolénico y linoleico que son los precursores de $\omega-3$ y $\omega-6$ respectivamente.

\section{PROCEDIMIENTO EXPERIMENTAL}

La materia prima utilizada en la presente investigación para elaborar el yogurt bebible y el queso fresco es leche proveniente de vacas del establo de la Universidad Nacional Agraria La Molina.

Aditivos para el yogurt bebible:

- Aceite de soya.

- Azúcar blanca.

- Gelatina incolora.

- Paquete "YoFlex 811" 
Aditivos para el queso fresco:

- Aceite de soya.

- Sal yodada al $100 \%$.

- Cloruro de calcio: Grado USP.

- Coagulante: CHY-MAX TM POWDER Extra, CHR HANSEN, 1 a $3 g$ por $100 \mathrm{~L}$ de leche.

\subsection{Elaboración del yogurt bebible enriquecido:}

Se descrema la leche a $50{ }^{\circ} \mathrm{C}$, luego se agrega el aceite de soya con el azúcar y la gelatina $(2 \mathrm{~g} / \mathrm{Kg})$, se agita y se pasteuriza a $85^{\circ} \mathrm{C}$ por $10 \mathrm{~min}$, se enfría a $43{ }^{\circ} \mathrm{C}$ para la inoculación de bacterias lácticas, se realiza la incubación a $42{ }^{\circ} \mathrm{C}$ por $5 \mathrm{~h}\left(\mathrm{pH}: 5,4\right.$ y acidez: $\left.70{ }^{\circ} \mathrm{D}\right)$, se enfría hasta $10{ }^{\circ} \mathrm{C}$, se realiza el batido, envasado y finalmente se almacena $4{ }^{\circ} \mathrm{C}$.

\subsection{Elaboración del queso fresco enriquecido:}

Se descrema la leche hasta aproximadamente $0,1 \%$ de grasa, luego se pasteuriza a $65{ }^{\circ} \mathrm{C}$ por $10 \mathrm{~min}$, se agrega luego el aceite de soya, se mezcla y se enfría hasta $50{ }^{\circ} \mathrm{C}$, a esta temperatura se agrega el cloruro de calcio, la mezcla se enfría hasta aproximadamente 37 $47^{\circ} \mathrm{C}$ para la coagulación por $45 \mathrm{~min}$, luego se realiza el corte de la cuajada $(2 \times 2 \mathrm{~cm})$, el desuerado, el salado por $10 \mathrm{~min}$, el moldeado y volteado por $45 \mathrm{~min}, \mathrm{y}$ finalmente se lleva a refrigeración por 24 h para luego desmoldar los quesos.

Para efectos del presente estudio se recopilan datos para comparar las mediciones de un grupo control (queso y yogurt elaborado sin aceite de soya), con las mediciones de un grupo experimental (queso y yogurt elaborado con aceite de soya), para el tratamiento de los datos se hace uso de un software estadístico.

Para los ensayos de elaboración del yogurt bebible enriquecido con aceite de soya, se considera como variables independientes la concentración de azúcar y la concentración de aceite de soya, se utilizan tres niveles como factores de estudio: bajo, medio y alto (Tabla 1).

Tabla 1. Niveles de Concentración para el yogurt

\begin{tabular}{|c|c|c|}
\hline Nivel & Azúcar $(\mathrm{g} / \mathrm{L})$ & Aceite $(\%)$ \\
\hline Bajo & 8 & $\mathbf{1}$ \\
\hline Medio & 9 & 2 \\
\hline Alto & 10 & 3 \\
\hline
\end{tabular}

Se plantea 9 formulaciones diferentes para el enriquecimiento del yogurt (Tabla 2 ).
Tabla 2. Diseño del yogur enriquecido

\begin{tabular}{|c|c|c|}
\hline Formulación & Azúcar $(\mathrm{g} / \mathrm{L})$ & $\%$ Aceite \\
\hline 1 & 10,0 & 2,0 \\
\hline 2 & 9,0 & 1,0 \\
\hline 3 & 10,0 & 3,0 \\
\hline 4 & 10,0 & 1,0 \\
\hline 5 & 9,0 & 3,0 \\
\hline 6 & 8,0 & 2,0 \\
\hline 7 & 9,0 & 2,0 \\
\hline 8 & 8,0 & 3,0 \\
\hline 9 & 8,0 & 1,0 \\
\hline
\end{tabular}

La aceptabilidad sensorial del yogurt se expresa a través de los siguientes atributos como variables dependientes:

- Gusto de sal.

- Textura.

- Apariencia general.

Para los ensayos de elaboración del queso fresco enriquecido con aceite de soya, se considera la concentración de sal y la concentración de aceite de soya como variables independientes, se utilizan tres niveles como factores de estudio: bajo, medio y alto (Tabla 3).

Tabla 3. Niveles de concentración para el queso

\begin{tabular}{|c|c|c|}
\hline Nivel & Sal (g/L) & Aceite (\%) \\
\hline Bajo & 14 & 2 \\
\hline Medio & 16 & 3 \\
\hline Alto & 18 & 4 \\
\hline
\end{tabular}

Se plantean 9 formulaciones diferentes para el enriquecimiento del queso (Tabla 4).

Tabla 4. Diseño del queso enriquecido

\begin{tabular}{|c|c|c|}
\hline Formulación & Sal (g/L) & \% Aceite \\
\hline 1 & 18,0 & 2,0 \\
\hline 2 & 18,0 & 4,0 \\
\hline 3 & 16,0 & 3,0 \\
\hline 4 & 14,0 & 4,0 \\
\hline 5 & 18,0 & 3,0 \\
\hline 6 & 16,0 & 4,0 \\
\hline 7 & 16,0 & 2,0 \\
\hline 8 & 14,0 & 3,0 \\
\hline 9 & 14,0 & 2,0 \\
\hline
\end{tabular}

La aceptabilidad sensorial del queso se expresa a través de los siguientes atributos como variables dependientes:

Acides.

Dulzor.

Viscosidad. 


\section{RESULTADOS}

En la tabla 5 se muestra los resultados del análisis de la leche descremada.

Tabla 5. Análisis de la leche descremada

\begin{tabular}{|c|r|}
\hline$\rho(\mathrm{g} / \mathrm{mL})\left(20^{\circ} \mathrm{C}\right)$ & 1.0334 \\
\hline Sólidos Totales (S.T.) & 9.053 \\
\hline$\%$ Grasa $\left(\mathrm{g}, 65^{\circ} \mathrm{C}\right)$ & 0.1 \\
\hline Acidez ${ }^{\circ}$ Dornic & 16.5 \\
\hline $\mathrm{pH}\left(16.7{ }^{\circ} \mathrm{C}\right)$ & 6.68 \\
\hline${ }^{\circ}$ Brix & 10.0 \\
\hline
\end{tabular}

Laboratorio de leche del Departamento de Producción Animal, Facultad de Zootecnia-UNALM (22/08/2011).

En la tabla 6 se muestra los resultados del análisis de la leche entera.

Tabla 6. Análisis de la leche entera

\begin{tabular}{|c|c|}
\hline$\rho(\mathrm{g} / \mathrm{mL})\left(20^{\circ} \mathrm{C}\right)$ & 1.0312 \\
\hline Sólidos Totales (S.T.) & 10.762 \\
\hline$\%$ Grasa $\left(\mathrm{g}, 65^{\circ} \mathrm{C}\right)$ & 2.0 \\
\hline Acidez ${ }^{\circ}$ Dornic & 17.5 \\
\hline $\mathrm{pH}\left(16.7^{\circ} \mathrm{C}\right)$ & 6.56 \\
\hline${ }^{\circ}$ Brix & 10.0 \\
\hline
\end{tabular}

Laboratorio de Leche del Departamento de Producción Animal, Facultad de Zootecnia-UNALM (22/08/2011).

Se analiza la composición de grasas del aceite de soya comercial (Tabla 7).

Tabla 7. Composición del aceite de soya comercial

\begin{tabular}{|l|c|}
\hline \multicolumn{1}{|c|}{ Descripción } & Resultado (\%) \\
\hline Grasa & 100 \\
\hline Ácidos grasos saturados & 15.42 \\
\hline Ácidos grasos monoinsaturados & 21.34 \\
\hline Ácidos grasos poliinsaturados & 59.71 \\
\hline Ácidos grasos no identificados & 3.53 \\
\hline
\end{tabular}

Fuente: Laboratorio INASSA - 02/09/2011

\subsection{Evaluación sensorial y análisis físico-químico del yogurt enriquecido con aceite de soya}

Para la evaluación sensorial participaron 70 personas, degustando $30 \mathrm{~mL}$ de yogur por juez. Los cuales califican los indicadores (acidez, dulzor y viscosidad) de cada formulación, para ello se usa una escala hedónica.

En las figuras 1,2 y 3 se grafican mediante diagrama de Pareto los efectos estimados de cada uno de los factores e interacciones en orden decreciente de importancia.

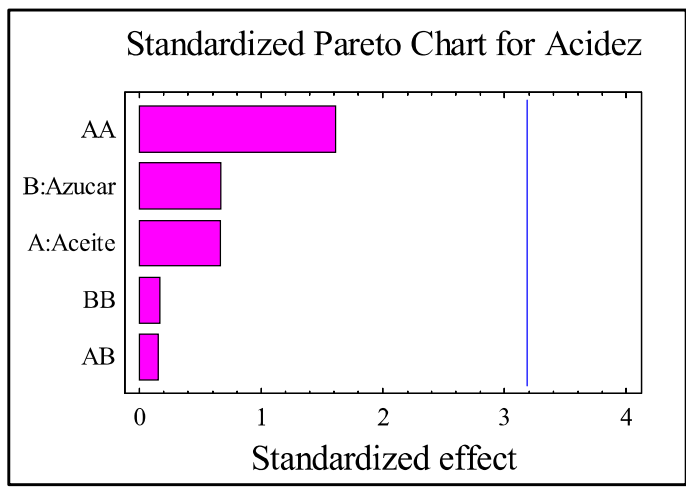

Figura 1. Diagrama de Pareto para el atributo de acidez.

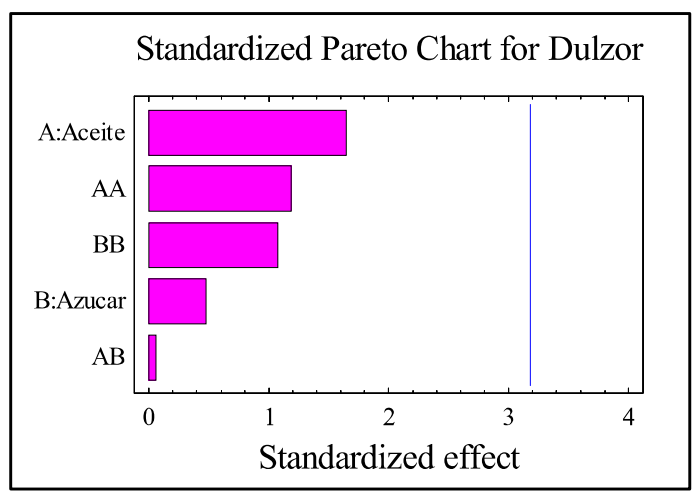

Figura 2. Diagrama de Pareto para el atributo de dulzor

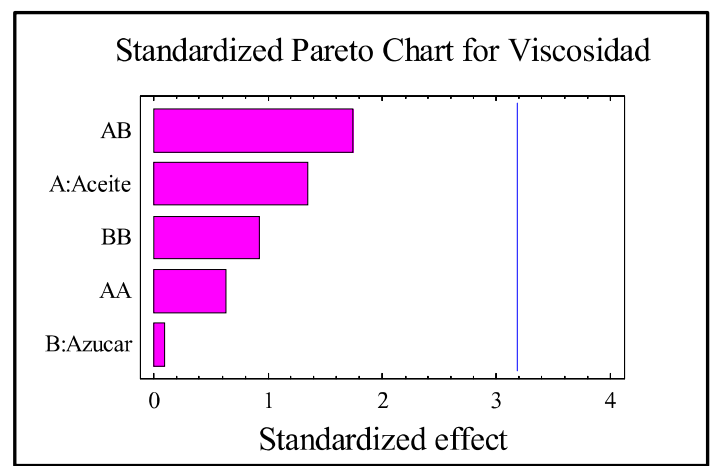

Figura 3. Diagrama de Pareto para el atributo de viscosidad.

El efecto estandarizado en las figuras 1,2 y 3 muestra el nivel de significancia de 3,2; el cual indica que ninguno de los factores o interacciones son significativas en la apreciación de la acidez, el dulzor y la viscosidad. 
Se estudia la superficie de respuesta que muestra la concentración en porcentaje de azúcar y aceite para determinar la máxima aceptabilidad en cada atributo.

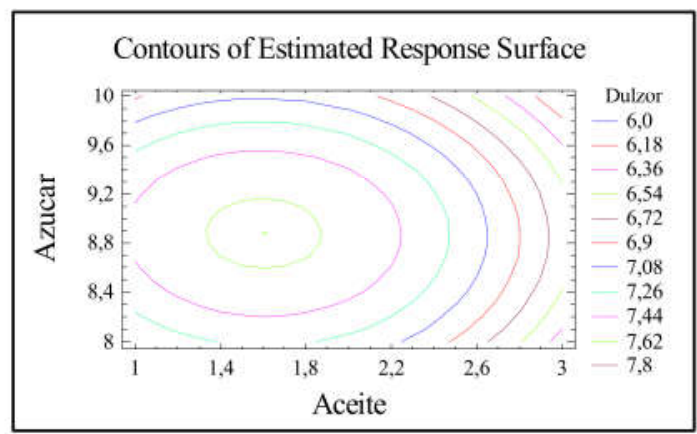

Figura 4. Contornos de la superficie de respuesta estimada del atributo dulzor

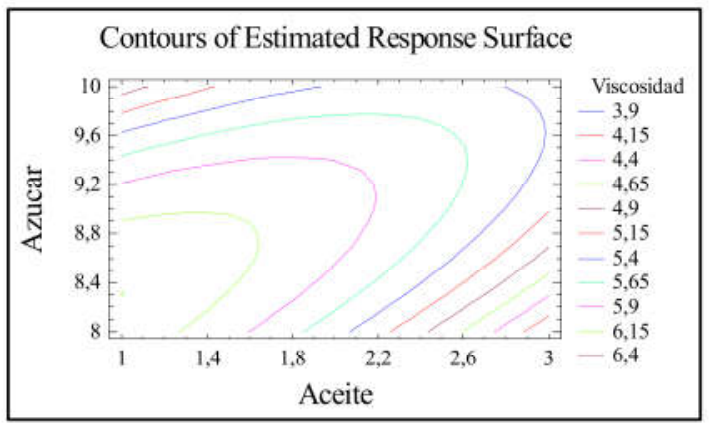

Figura 5. Contornos de la superficie de respuesta estimada del atributo viscosidad.

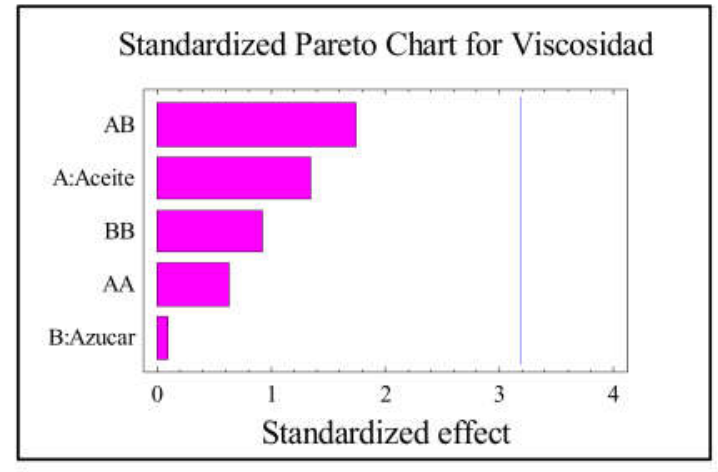

Figura 6. Contornos de la superficie de respuesta estimada del atributo acidez

En la elaboración del yogurt se evalúa los factores y atributos óptimos reportados por el software (Tabla 8).

Tabla 8. Niveles óptimos de los factores para el yogurt enriquecido

\begin{tabular}{|c|c|c|c|c|}
\hline Factores & Bajo & Medio & Alto & Óptimo \\
\hline Azúcar (g/L) & 8.0 & 9.0 & 10.0 & 8.73747 \\
\hline Aceite (\%) & 1.0 & 2.0 & 3.0 & 1.66116 \\
\hline
\end{tabular}

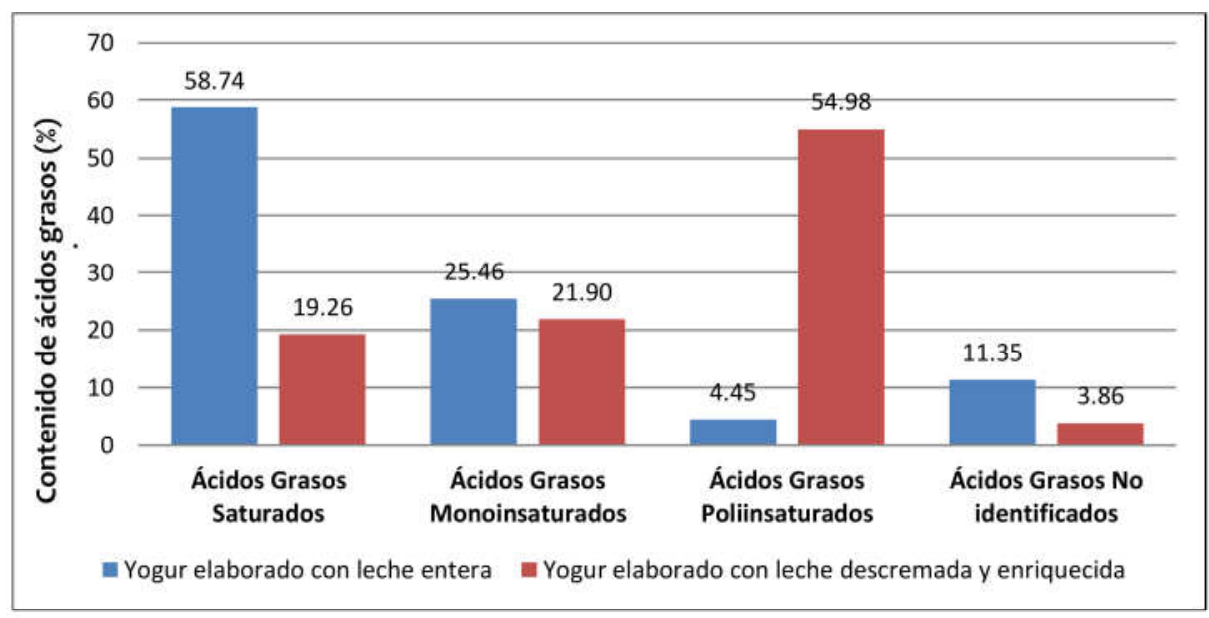

Figura 7. Composición porcentual de la grasa contenida en el yogur. 
El contenido de ácidos grasos poliinsaturados en el yogurt elaborado con leche entera es de $4,45 \%$ y luego del descremado de la leche y enriquecimiento con aceite de soya se incrementa hasta 54,98\% (Figura 7).

Tabla 9. Valoración de atributos del yogur óptimo

\begin{tabular}{|c|c|}
\hline Respuesta & Óptimo* \\
\hline Acidez & 7.50483 \\
\hline Dulzor & 7.64852 \\
\hline Viscosidad & 6.14417 \\
\hline
\end{tabular}

*De un total de 10 unidades.

Luego de analizar los datos con software estadístico se obtienen los valores óptimos para los niveles (Tabla 8), y los valores óptimos para los atributos del yogurt enriquecido (Tabla 9).

Se realiza finalmente análisis fisicoquímico al yogurt óptimo elaborado (Tabla 10).

Tabla 10. Análisis Fisicoquímico del yogur enriquecido óptimo

\begin{tabular}{|l|c|}
\hline \multicolumn{1}{|c|}{ Composición } & $\begin{array}{c}\text { Azúcar }(\mathrm{g} / \mathrm{L}): 8.3 \\
\text { Aceite }(\%): 1.0\end{array}$ \\
\hline $\mathrm{pH}$ & $4.30\left(25,0^{\circ} \mathrm{C}\right)$ \\
$\begin{array}{l}\text { Acidez }{ }^{\circ} \text { Dornic } \\
\text { Viscosidad cP }\end{array}$ & 47.0 \\
\hline
\end{tabular}

\subsection{Evaluación sensorial y análisis fisicoquímico del queso fresco enriquecido con aceite de soya}

Para la evaluación sensorial del queso participaron 100 personas, degustando $30 \mathrm{~g}$ de queso por juez. Los cuales califican los indicadores (Gusto de sal, textura y apariencia general) de cada formulación, para ello se usa una escala hedónica.

En los gráficos 8, 9 y 10 se plotea los efectos estimados de cada uno de los factores e interacciones en orden decreciente de importancia.

El efecto estandarizado en las figuras 8 y 9 muestra el nivel de significancia de 3,2 para las interacciones, el cual indica que ninguno de los factores o interacciones son significativas en la apreciación del gusto de sal y textura.

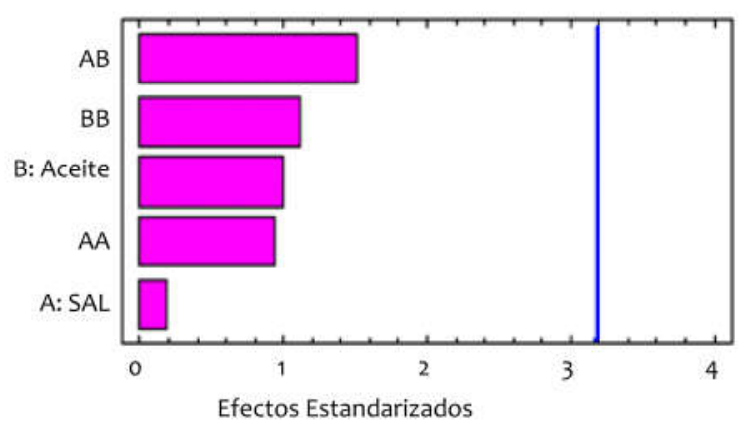

Figura 8. Diagrama de Pareto para el gusto de sal

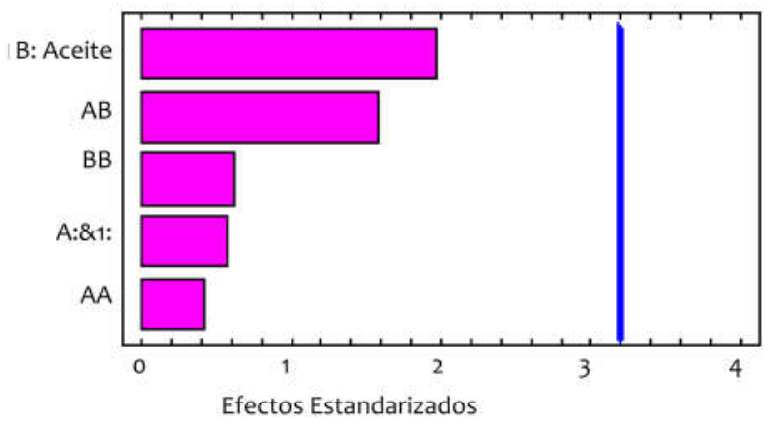

Figura 9. Diagrama de Pareto para el atributo textura

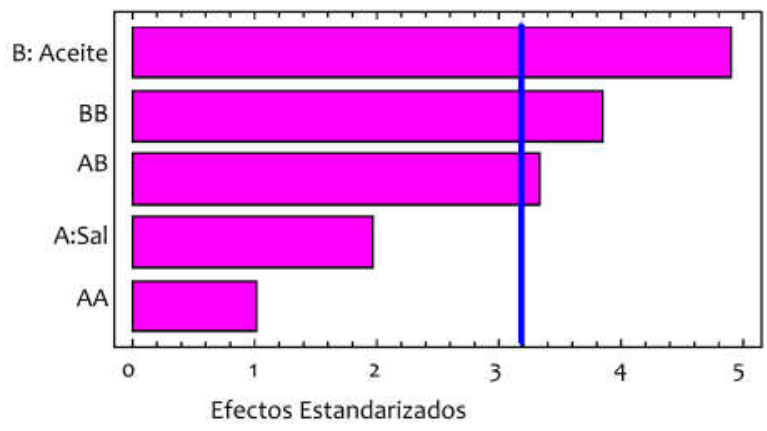

Figura 10. Diagrama de Pareto para el atributo apariencia.

El efecto estandarizado en la figura 10 muestra el nivel de significancia 3,2 e indica que el efecto del factor aceite (B) y la interacción aceite - aceite (BB) y aceite-sal $(A B)$ es significativo en la apreciación del atributo apariencia

Se estudia la superficie de respuesta que muestra la concentración en porcentaje de sal y aceite para determinar la máxima aceptabilidad en cada atributo. 


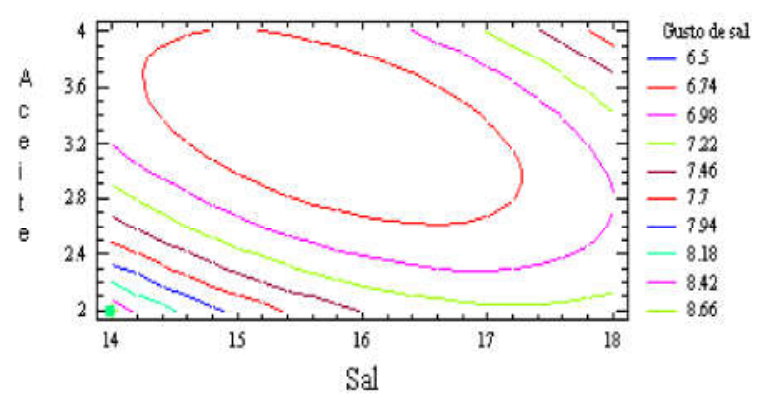

Figura 11. Contornos de la Superficie de Respuesta Estimada del atributo gusto de sal

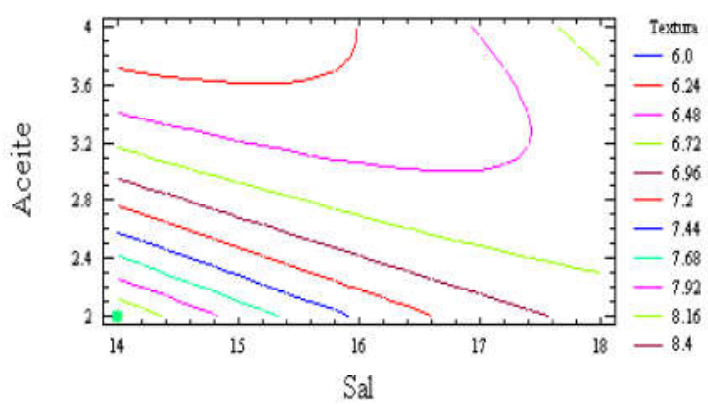

Figura 12. Contornos de la Superficie de Respuesta Estimada del atributo textura

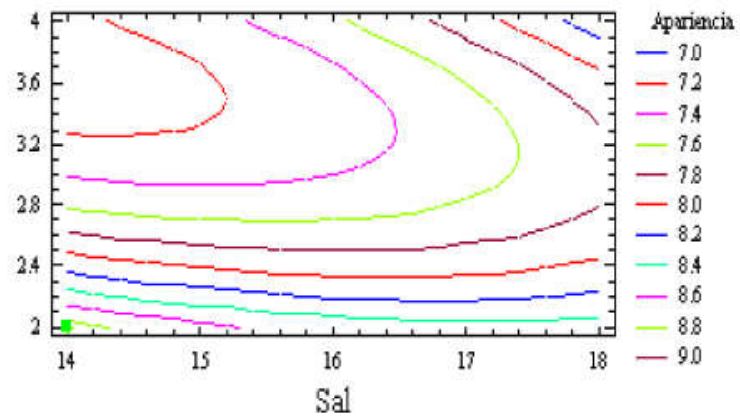

Figura 13. Contornos de la Superficie de Respuesta Estimada del atributo apariencia

En la elaboración del queso enriquecido con aceite de soya se evalúa los factores y atributos óptimos reportados por el software estadístico (Tabla 11).

Tabla 11. Niveles óptimos de los factores para el queso enriquecido

\begin{tabular}{|c|c|c|c|c|}
\hline Factores & Bajo & Medio & Alto & Óptim \\
\hline Sal (g/L) & 14 & 16 & 18 & 14 \\
\hline Aceite (\%) & 2.0 & 3.0 & 4.0 & 2.0 \\
\hline
\end{tabular}

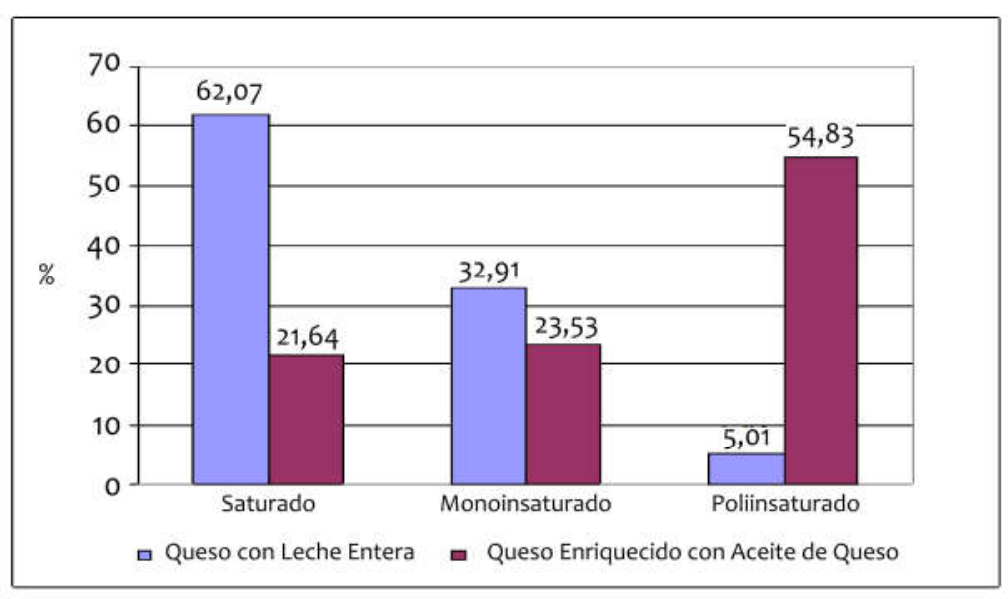

Figura 14. Composición porcentual de grasas en el queso

El contenido de ácidos grasos poliinsaturados en el queso elaborado con leche entera es de 5,01\% y luego del descremado de la leche y enriquecimiento con aceite de soya se incrementa hasta 54,83 \% (Figura 14).
Luego del analizar los datos con software estadístico se obtienen los valores óptimos para los niveles (Tabla 11), y los valores óptimos para los atributos del queso enriquecido (Tabla 12).

Tabla 12. Valoración de atributos del queso óptimo

\begin{tabular}{|c|c|}
\hline Respuesta & Óptimo* \\
\hline Custo de sal & 8.543 \\
\hline Textura & 8.361 \\
\hline Apariencia & 8.877 \\
\hline
\end{tabular}

*De un total de 10 unidades. 


\section{CONCLUSIONES}

Las concentraciones óptima de aceite de soya y azúcar sensorialmente aceptados para la elaboración de yogurt enriquecido son $1.66 \%$ y $8.74 \%$ respectivamente. $\mathrm{Y}$ las concentraciones óptimas de aceite de soya y sal sensorialmente aceptadas para la elaboración de queso fresco enriquecido son $2 \%$ y $14 \%$ respectivamente.

Se determina que el contenido de ácidos grasos poliinsaturados que contiene el queso fresco elaborado con leche entera es de 5,01\%, y se incrementa a 54,83\% para el queso fresco elaborado con leche descremada y enriquecido con aceite de soya. Para el yogurt, el contenido de ácidos grasos poliinsaturados que contiene el yogurt elaborado con leche entera es de $4,45 \%$, y se incrementa a 54,98\% para el yogurt elaborado con leche descremada y enriquecido con aceite de soya.

Se evalúa las propiedades sensoriales del queso fresco enriquecido correspondientes a la formulación, sal $14 \mathrm{~g} / \mathrm{L}$ y aceite 2,0 \%; el resultado es: sabor 8,54; textura 8,36 y apariencia 8,88 de un total de 10,0 unidades lo que demuestra su aceptabilidad sensorial.

Se evalúa también las propiedades sensoriales del yogurt bebible enriquecido correspondientes a la formulación, azúcar $8,3 \mathrm{~g} / \mathrm{L}$ y aceite $1,0 \%$; el resultado es: acidez 7,50; dulzor 7,65 y viscosidad 6,14 de un total de 10,0 unidades lo que demuestra su aceptabilidad sensorial.

Sí es posible producir yogur bebible y queso fresco enriquecido con ácidos grasos poliinsaturados de aceite de soya que sea aceptado sensorialmente.

\section{REFERENCIAS}

[1] F. Leighton, "Dietas mediterraneas 6," Boletín ciencia, vino y salud, vol. 1, pp. 1 - 20, 2002

[2] C. Alais, Ciencia de la leche, España: Reverte S.A., 1985.

[3] MINAG, "Estadística Agraria Mensual," Oficina de Información Agraria, Perú, 2011.

[4] J. Dubach, El ABC para la quesería rural de los andes, Ecuador: ABC, 1988.

[5] B. Blanco, C. Alvarado y U. Ortiz, Alimentos Bromatología, Perú: Talleres Gráficos de Mercado Abierto S.A.C., 2003.

[6] A. Aigster, C. Sims, R. Staples, R. Schmidt y S. O'Keef, "Comparison of cheeses made from milk having normal and high oleic fatty acid compositions," J. Food Sci., vol. 5, pp. 920 924, 2000.

[7] D. Badui, Química de los alimentos, México: Alhambra, 1996.

[8] R. Early, Tecnología de los productos, Zaragosa: Acriba S.A., 1998.

[9] O. Fennema, Química de los alimentos, España: Acribia, 2000

[10] M. Ureña, M. D’Arrigo y O. Girón, Evaluación sensorial de los alimentos, Lima: Editorial agraria, 1999.

[11] INDECOPI, Leche y productos lácteos. Queso fresco. Requisitos. Norma Técnica Peruana: NTP 202.195 2da edición, Lima - Perú, 2004 . 